\begin{tabular}{c} 
International Journal of Engineering \& Technology, 7 (4) (2018) 2704-2709 \\
International Journal of Engineering \& Technology \\
SPC \\
$\begin{array}{c}\text { Website: } \text { www.sciencepubco.com/index.php/IJET } \\
\text { doi: } 10.14419 / \text { ijet. } v 744.14879 \\
\text { Research paper }\end{array}$ \\
\hline
\end{tabular}

\title{
An investigation on design innovation, fabrication and experiment of a soy bean peeling machine-scale
}

\author{
Van Thanh Tien Nguyen ${ }^{1 *}$, Van Anh Dang ${ }^{1}$, Ngoc Thoai Tran ${ }^{1}$, Cong Hoang Nguyen ${ }^{2}$, Dai Hoa Vo ${ }^{2}$, Dang Khoa \\ Nguyen $^{2}$, Ngoc Lam Nguyen ${ }^{2}$, Quang Lam Nguyen ${ }^{2}$, Thien Long Tieu' ${ }^{2}$, Tan Nam Bui ${ }^{2}$, and Tien Bao Tran ${ }^{2}$ \\ ${ }^{1}$ Lecturer, Faculty of Mechanical Technology, Industrial University of Ho Chi Minh city \\ ${ }^{2}$ Undergraduate student, Faculty of Mechanical Technology, Industrial University of Ho Chi Minh city \\ *Corresponding author E-mail: nguyenvanthanhtien@iuh.edu.vn
}

\begin{abstract}
This study on the mentioned machine is to intend to peel seed coat of dried soybean that applies the friction principles between the seed coat and the conveyor belt. Creating largely frictional contact on the surface of the soybeans leads to the broken link of the seed coat which is responsible for peeling away the seed coat from the soybeans completely. This work demonstrates the design parameters and the fabrication method including the number of rotations of the two conveyors, the contact distance between the conveyor and soybeans. The recommended values of the parameters after studying are carried out as following: the revolution is $120 \mathrm{rpm}$, the gap between the conveyor and the bean is $6 \mathrm{~mm}$ and the conveyor belt width is $400 \mathrm{~mm}$. Based on these results, the finished product reaches around 80.06 percent and the productivity achieves 15 kilograms per hour.
\end{abstract}

Keywords: Peeling Machine; Soy Bean Processing Machine; Soy Bean Seed Coat Removing Equipment; Dried Soybean Detaching Machine.

\section{Introduction}

The peeling dried soybean machine is a compound machine having performance depending on frictional contact on the surface of the soybeans. A contact gap is determined by the distance between the conveyor and the soybean. The number of rotations of the two conveyors plays an important role to satisfy the moving ability of the bean. In addition, the width of the conveyor belt has an impact on not only the area of contact but also the number of soybeans on the conveyor belt. Besides, soybean moisture plays a critical role in the link between the soybean and its seed coat. The conveyor has been developed and applied around the world. The production process of the conveyor helps to collect data, monitor, process parameters to control, optimize the operation of equipment, and the technology process requiring high reliability.

The peeling dried soybeans machine is the equipment used to peel the seed coat from the dried soybean. This kind of machine is not popular in the market at present. Nevertheless, there are several machines developed by individual such as Nguyen Tan Bien's the peeling wet bean machine which was appeared on VTC6 of Viet Nam national channel. The dried soybean peeling machine studied by a group of students of Ho Chi Minh city University of Technology and Education, Viet Nam. There are a few dried soybean machines such as: Soybean machine HH-TK-300, HH-TK-400, HH-TK-500A made by Zukun of Germany. Soybean machine TNĐ-Yamaguchi was made in Japan and other studies have been done from many countries.

The peeling dried soybean machine has superior merits compared to other kinds of peeling machine such as low broken soybean owing to good frictional interaction between the conveyor belt and soybean, more uniform products, spare parts could be found easi- ly, investment and fabrication costs of peeling dried soybean which are significantly lower than many types of rotary barrel peeling machine. Nevertheless, this machine has a few drawbacks including low product rate, and the machine has a short working lifetime because of using the conveyor mainly to operate. If the requirements, which are including the humidity of the soybeans within limits and the equal high the soybean size, could not be controlled. The machine will not be able to achieve the productivity as expected. With those small sized-beans when peeled, they may be moved out the peeling system and with those bigger sizedbeans can be crushed.

It is easily seen that there are not many companies producing the peeling dried soybean machine and the kind of this machine is not diversified in order to make a choice. Therefore, designing and manufacturing the machine are extremely potential and fully promised.

\section{Soybean coat peeling principles and ma- chine design processes}

\subsection{Calculational parameters of testing}

Table 1: Specifications of Basic Parameters for the System

\begin{tabular}{lll}
\hline Specification & Value & $\mathrm{unit}$ \\
\hline Productivity & 15 & $\mathrm{~kg} / \mathrm{h}$ \\
Velocity of conveyor A & 0.35 & $\mathrm{~m} / \mathrm{s}$ \\
Velocity of conveyor B & 0.45 & $\mathrm{~m} / \mathrm{s}$ \\
Motor A & 675 & $\mathrm{rpm}$ \\
Motor B & 675 & $\mathrm{rpm}$ \\
Size of conveyor A & $2640 \times 400$ & $\mathrm{~mm}$ \\
Size of conveyor B & $3200 \times 400$ & $\mathrm{~mm}$ \\
\hline
\end{tabular}

Copyright $\odot 2018$ Van Thanh Tien Nguyen et al. This is an open access article distributed under the Creative Commons Attribution License, which permits unrestricted use, distribution, and reproduction in any medium, provided the original work is properly cited. 


\subsection{Seed coat peeling principles}

Peeling soybeans is a process which breaks the link between the cotyledon and the seed coat. The process applies the principle that two conveyors are installed in parallel and operated in opposite directions, with a certain gap. The main working parts are two exposed surfaces of the conveyors which have appropriate speed and gap to detach the processing soybeans.

The machine for peeling dried soybean was studied on fifteen kilograms per hour which was done experiments at Industrial University of Ho Chi Minh city, Viet Nam. Soybeans are dried then delivered through peeling machine with the technology using two conveyors that rotate counter clockwise creating friction to detach its cotyledon from the seed coat. The velocity and the gap between the conveyor and the soybean seed coat are appropriately adjusted for the purpose of creating the best peeling process.

To detach its seed coat from the soybeans, the necessary force needs to be applied on the soybeans. Friction is important for peeling, therefore, the capacity of the two conveyors has to be computed, the rotational speed has to be found out and the gap has to be ensured the products exceeding more than 80percent.

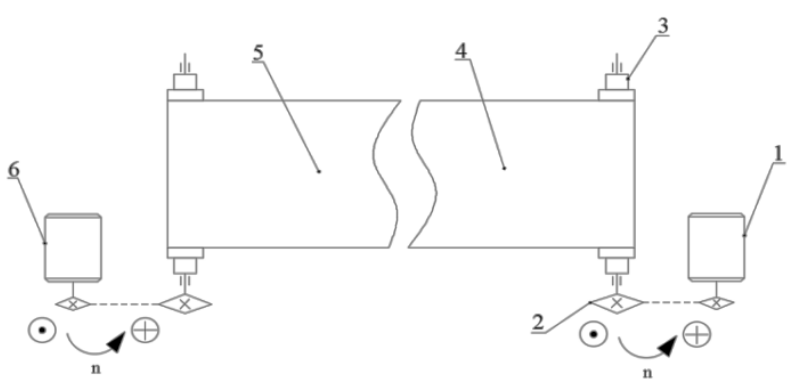

1) Motor A, 2) Sprocket and chain system, 3) Drum shaft-roller, 4) Top Conveyor A, 5) Bottom Conveyor belt B, 6) Motor B

Fig. 1: Experimental Machine-Scale Drawing Side for Peeling Soybeans.

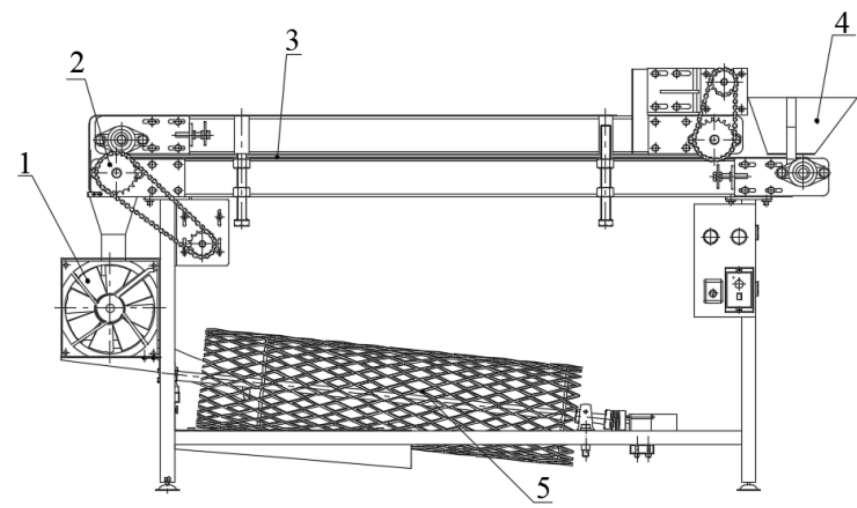

1- Air blower; 2- Sprocket and chain system; 3- Working area of the system; 4- Supplied soybean raw part; 5 Soybean classifiers

Fig. 2: Principle Diagram of the System.

When the engine A (1) works, its shaft will rotate and create transmission of moment through the sprocket and chain system (2) to rotate the drum shaft-rotate (3) and operate the conveyor belt $\mathrm{A}$ (4). Like the engine A (1), the engine B (6) operates the conveyor belt $\mathrm{B}(5)$. The two motors have different rotation. The soybean will be pressed between the two conveyors (4) and (5), because the two surfaces of the two conveyors work in the opposite directions. The conveyor B (5) works faster than conveyor A (4) to orient the soybean. The motor B (6) will be equipped with an inverter that can be changed the best suitable speed of the conveyors. Fig. 2 shows that the conveyor belts and the rollers on the shaft are important parts in this design.

\subsection{Machine-scale design}

\subsubsection{Selecting the conveyor}

Table 2: Comparison of Three Types of Conveyors

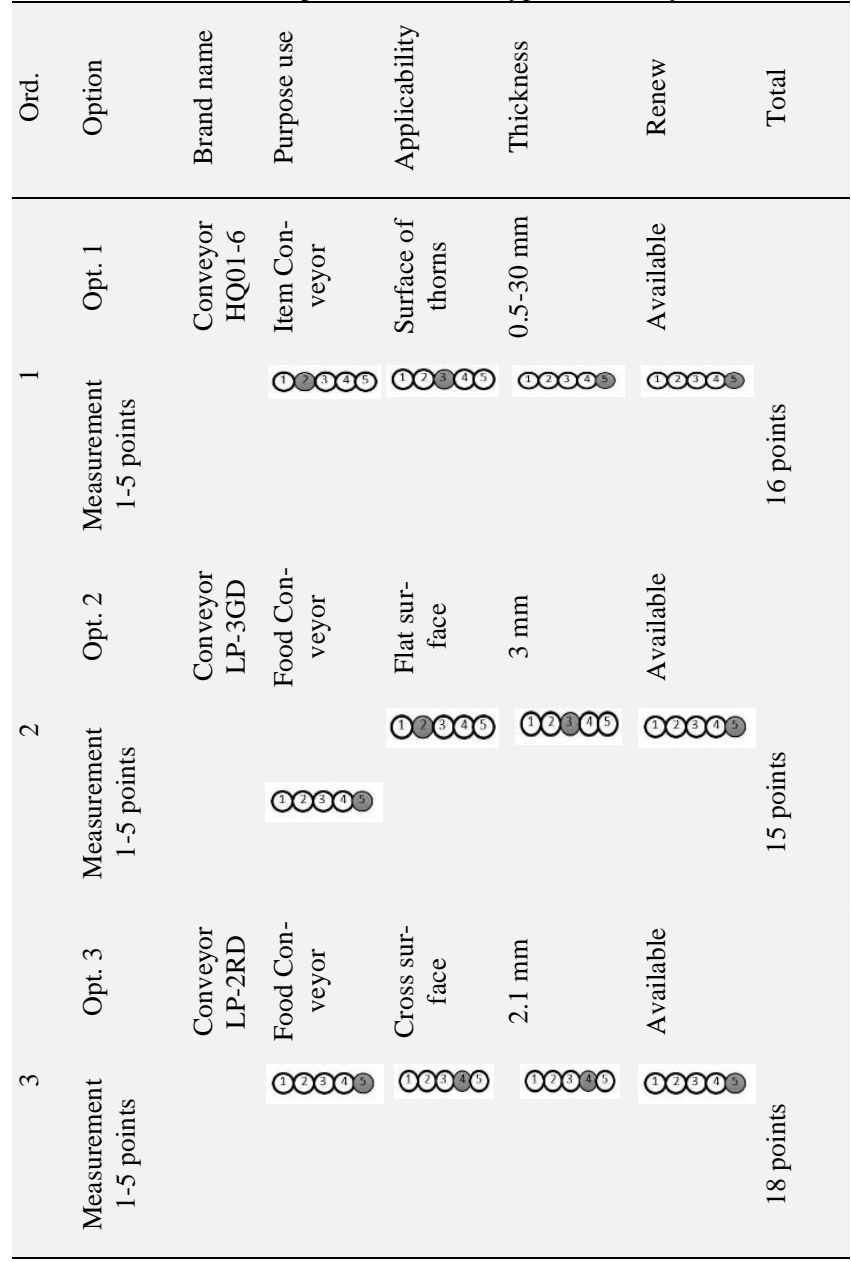

Evaluation concept of table 2

The concept for assessing the conveyor belt selected in accordance with the machine includes the level of 1 is rated weak, the level 2 is below average, the level 3 is average, the level 4 is good and the level 5 is excellent.

Table 2 presents that to ensure food safe. In addition, Opt. 1 is the worst because Opt. 2 and Opt.3 are the types of conveyor belt providing for the food processing industry. With peeling capacity, there are many kinds of thickness that are the most suitable for comparing to all the rest. Moreover, it is clear to see that the Opt.3 is the best one. This machine is only a machine modeling for testing a small model scale, therefore, the greater its thickness is, the harder it could work. The rollers have to be designed with a big diameter to fit the curve angle of the conveyors. Besides, this requires a motor with high capacity which would increase more cost The Opt. 3 is the most appropriate for this study.

\subsubsection{Design machine parts and machining the drum shaft-} rollers.

\section{Design of components}

The part has typical form is stepped shaft. Its function is to drive conveyor [4]. Its specifications are required when designing parts. Reliability, durability and assembly ability of the drum shaft-roller are precisely defined with the requirements. Two precise bearings were machined with the exact level 7 and the smoothness of the surface is grade 8 [4], [6]. Errors of the drum shafts-roller compared with its central line are less than $0.05 \mathrm{~mm}$. Setting up the experimental process and calculating internal force process. 
First of all, two sides of shaft head surfaces were turned by a lathe machine. Then their central holes were drilled by a semi automatically drilling machine before they were used for selecting the finely fixing standard during the machining process. [4], [7] and [8].

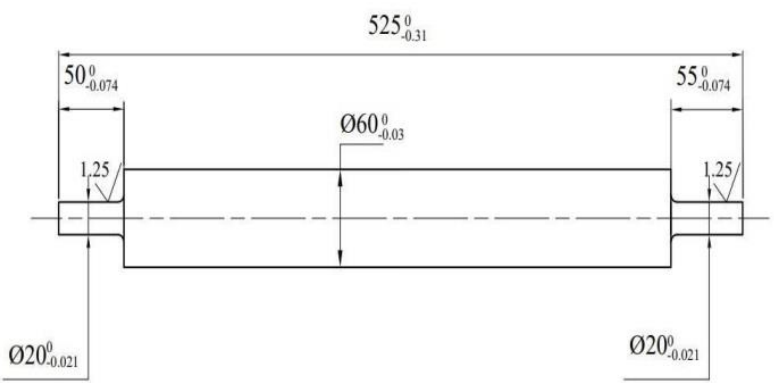

Fig. 3: Drum Shaft-Roller Drawing.

Internal force diagram of the driven shaft

Tangent force:

$\mathrm{F}_{\mathrm{b}}=\frac{6120 \times P}{v}[9]$

Tension on two sides of the conveyor:

$F=F_{b} \frac{e^{\theta \mu}}{e^{\theta \mu-1}}[9]$

C45 steel was chosen for the designing the shafts:

$\mathrm{HB}=240, \delta_{b}=700 \mathrm{MPa}, \delta_{c}=480 \mathrm{MPa}[\tau]=30 \mathrm{Mpa}[7]$.

Reacting force at bearings at Oxz plan:

$\sum M_{A}=Y_{B} \times 460-F_{x} \times 30-\frac{G}{2} \times 20-\frac{G}{2} \times 440=0[8]$

Therefore,

$Y_{B}=89,76 \mathrm{~N}$

and there is

$\sum F_{Y}=Y_{B} \cdot-G+F_{x}-Y_{A}=0[8]$.

Therefore,

$Y_{A}=642.76 \mathrm{~N}$

Reacting force at bearings at Oyz plan:

$\sum M_{A}=-X_{B} \times 460+R_{1} \times 20+R_{2} \times 440=0[8]$.

Therefore,

$X_{B}=295.83 \mathrm{~N}$

and there is

$\sum F_{Y}=X_{A}+X_{B}-R_{1}-R_{2}=0[11]$

Therefore,

$X_{A}=691.17 \mathrm{~N}$

Hazardous position at position $\mathrm{C}$ in the table 10.6[7] shows the torque and the torque reaction.

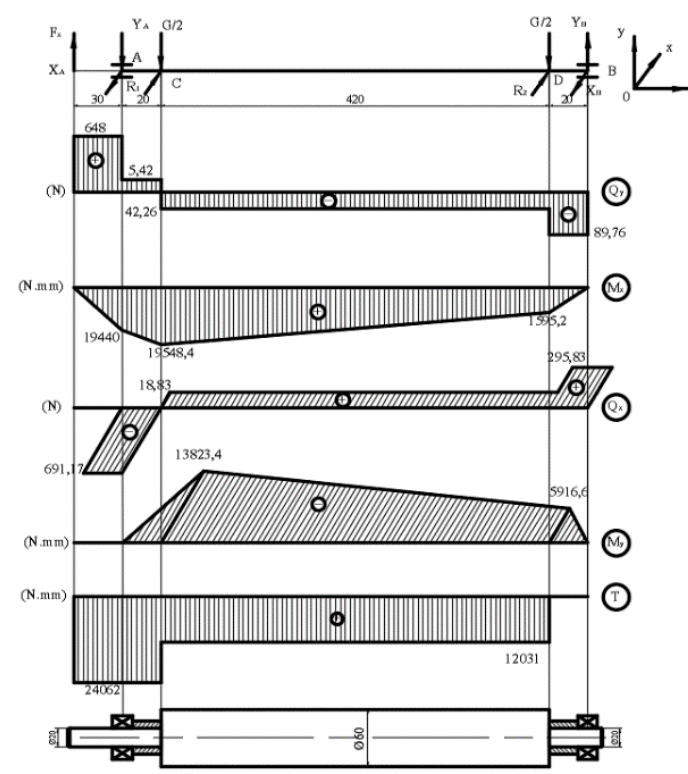

Fig. 4: Internal Force Moment and Torque Diagram (4).

$W_{j}=\frac{\pi \times d^{3}}{32}=21205.75 \mathrm{~mm}^{3}$

and,

$W_{o j}=\frac{\pi \times d^{3}}{16}=42411.5 \mathrm{~mm}^{3}$

Shaft structuring is designed to ensure the fatigue if safety factors at dangerous sections meets the initial conditions.

$S=\frac{S_{\sigma^{\times}} S_{\tau}}{\sqrt{S^{2}{ }^{2}+S_{\tau}^{2}}}=33.61>[\mathrm{S}]=1.5$

Therefore, it meets conditions [5].

$\sigma=\frac{M_{\max }}{0,1 \times d^{3}}=\frac{19548,4}{0,1 \times 60^{3}}=0,9 M P a \leq[\sigma]=50 M P a$

and,

$\tau=\frac{T_{\max }}{0,1 \times d^{3}}=\frac{24062}{0,2 \times 60^{3}}=0,56 M P a \leq[\tau]=15 M P a$

\subsubsection{Simulation of the frame stress}

The body frame made of CT3 steel, is able to work with load of $800 \mathrm{~N}$ and the height of that is $600 \mathrm{~mm}$.

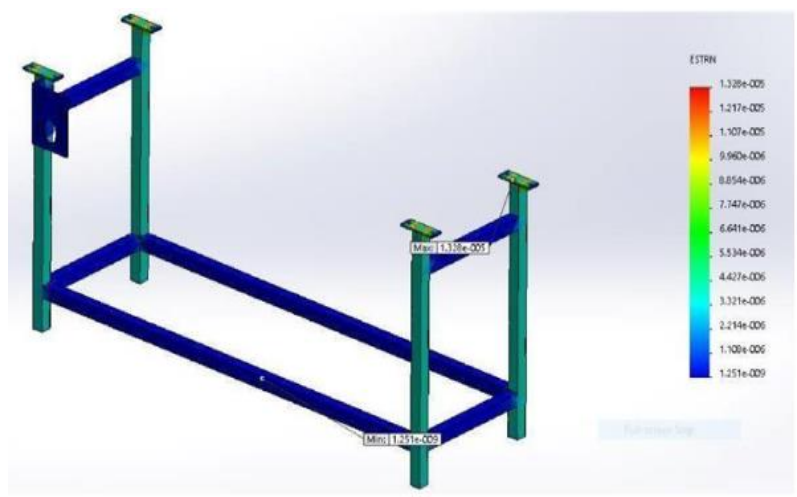

Fig. 5: Stress Distribution on the Designed Body Frame. 


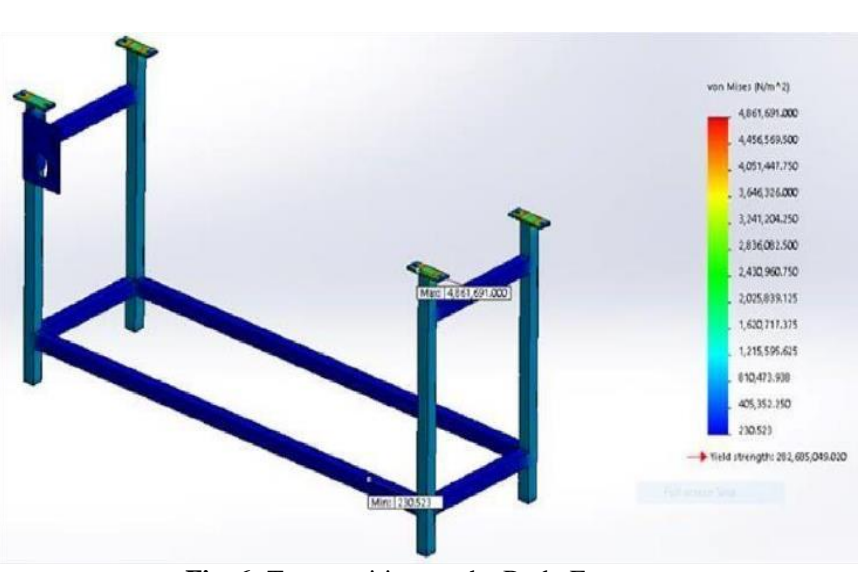

Fig. 6: Transposition on the Body Frame.

\subsection{The gap between the two conveyors}

The equipment used to measure the gap is TPG-700A Niigata with its code standing for TPG-700A, and its brand name is Niigata (SK) made in Japan.

Table 3: Gap Parameter Measurement TPG-700-Niigata

\begin{tabular}{lll}
\hline Parameter & Value & Unit \\
\hline Measurement range & $1 \sim 15$ & $\mathrm{~mm}$ \\
Accuracy & \pm 0.05 & $\mathrm{~mm}$ \\
Dividing line & 0.1 & $\mathrm{~mm}$ \\
Cone angle & 0.125 & $\mathrm{rad}$ \\
Length & 148.5 & $\mathrm{~mm}$ \\
Thickness & 1.2 & $\mathrm{~mm}$ \\
Weight & 10 & $\mathrm{~g}$ \\
\hline
\end{tabular}

\section{Experimental settings}

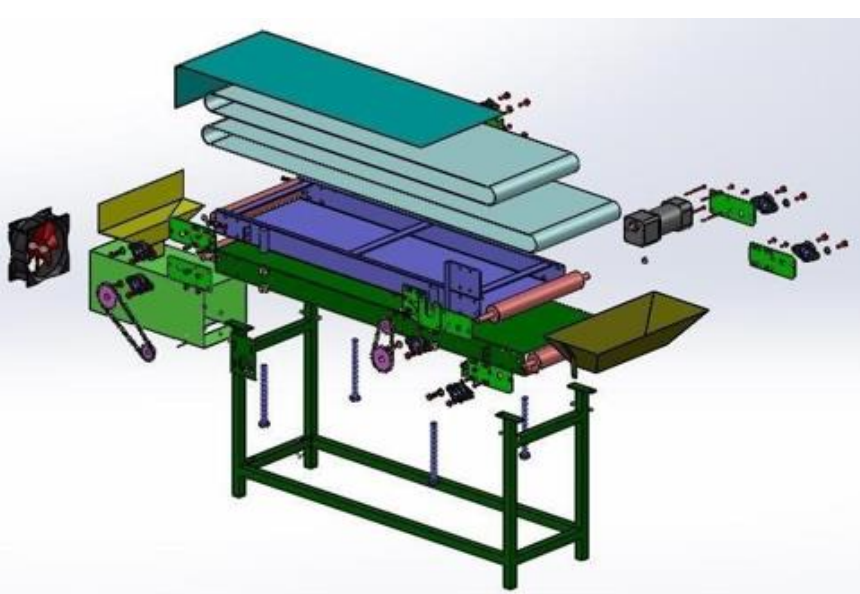

Fig. 7: The Assembly Drawing of the Soy Bean Peeling Machine

\section{Experimental description}

The experimental in reality is researched by supplying 250 grams of soybeans the machine to operate through adjusting two main factors that are the gap between the conveyor and soybeans and the speed rotation of the two conveyors. The gaps conducted to the experiments with the gaps of $5,6,7$ and $8 \mathrm{~mm}$. The conveyor speed levels conducted to experiments with 45, 60, 70, 92, 100, $110,120,133$ and $145 \mathrm{rpm}$. In order to achieve optimum accuracy, the number of experiments which is conducted the gaps and the velocity between of the two conveyors for each experiment at least 5 times. The machine, which could be see in Fig. 7 for peeling soybean, has been successfully manufactured with a capacity of 15 kilograms per hour. With this machine, there will be the replacement of workers to get higher productivity and ensure the food safety.

\section{Experimental results and discussion}

\subsection{Results of the experiments - 1}

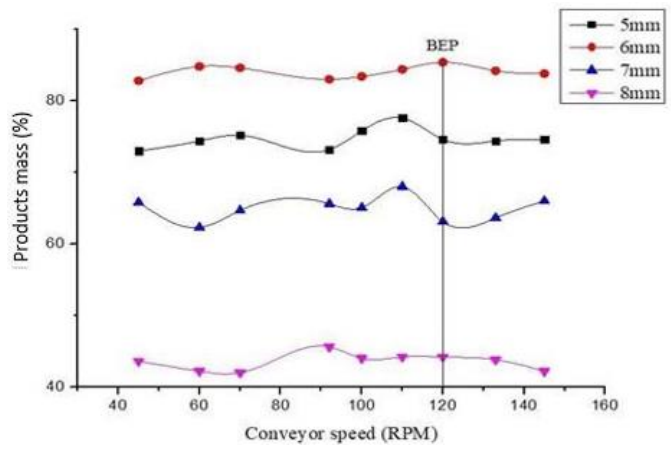

Fig. 8: The Relationship between the Rate of Products with the Gaps of the Two Conveyors and the Bean and the Speed of the Top Conveyor.

The results of testing of the experiments 1 can be seen that in the Fig. 8 which shows that with the gap of $6 \mathrm{~mm}$, there is the highest weigh of productivity compared with all the rest. With the speed level is $120 \mathrm{rpm}$, there is the highest productivity. To have the best result, the parameter should be set at $6 \mathrm{~mm}$ for the gap respectively and $120 \mathrm{rpm}$ for the speed of the conveyors; the experimental 2 and 3 are then conducted.

\subsection{Results of the experiments -2}

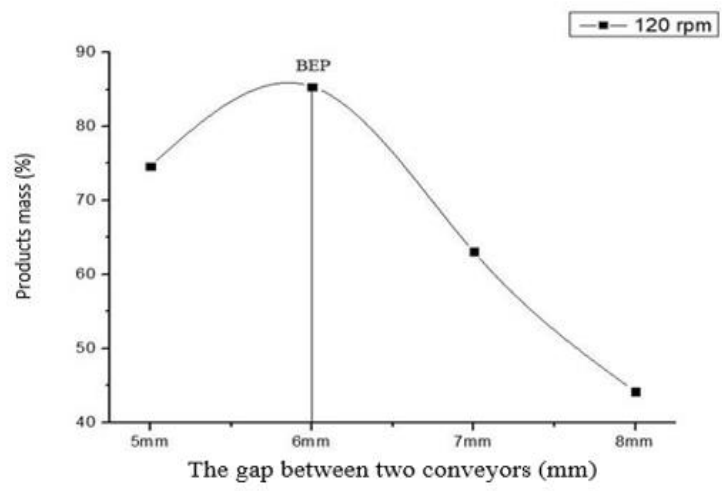

Fig. 9: The Relationship between Product Rate and the Gaps of the Two Conveyors.

Experimental results in Fig. 9 show that when the gap increases from $5 \mathrm{~mm}$ to $6 \mathrm{~mm}$, the volume of fine products will raise. If we continue to increase the gap exceeding $6 \mathrm{~mm}$, the volume of fine products gradually reduced. Therefore, the best gap in the experiment is $6 \mathrm{~mm}$.

\subsection{Results of the experiments -3}

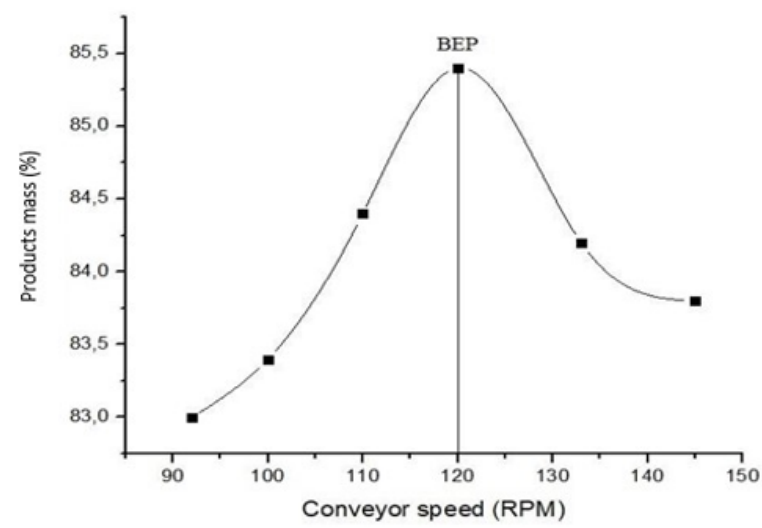

Fig. 10: Relationship between Finished Rate and Speed of Top Conveyor 
Fig. 10 shows that when the speed increases up to $120 \mathrm{rpm}$, the product mass will respectively increase. Continuously increasing the speed faster than $120 \mathrm{rpm}$, the volume of products will decrease. Therefore, the best speed should be in the experiment 120 rpm.

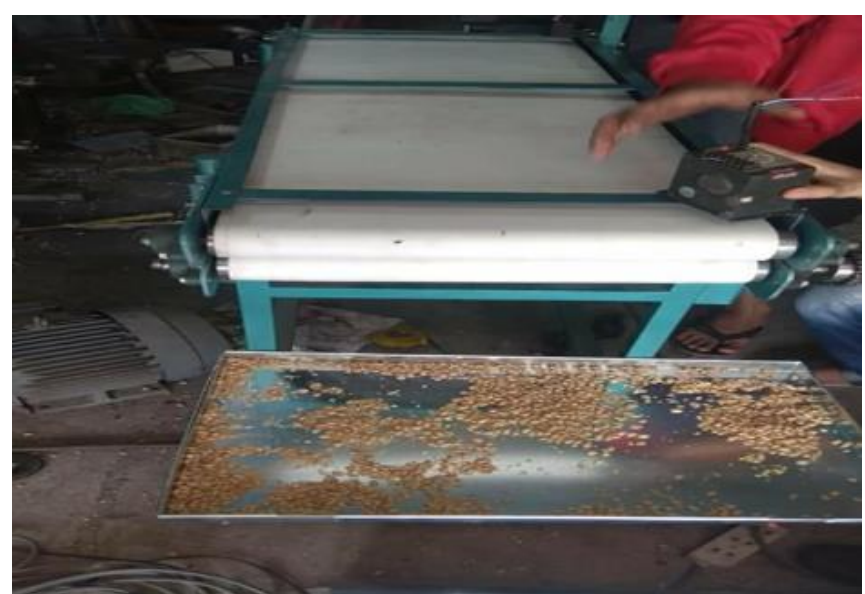

Fig. 11: Experiments Practiced on the Machine after Fabricating

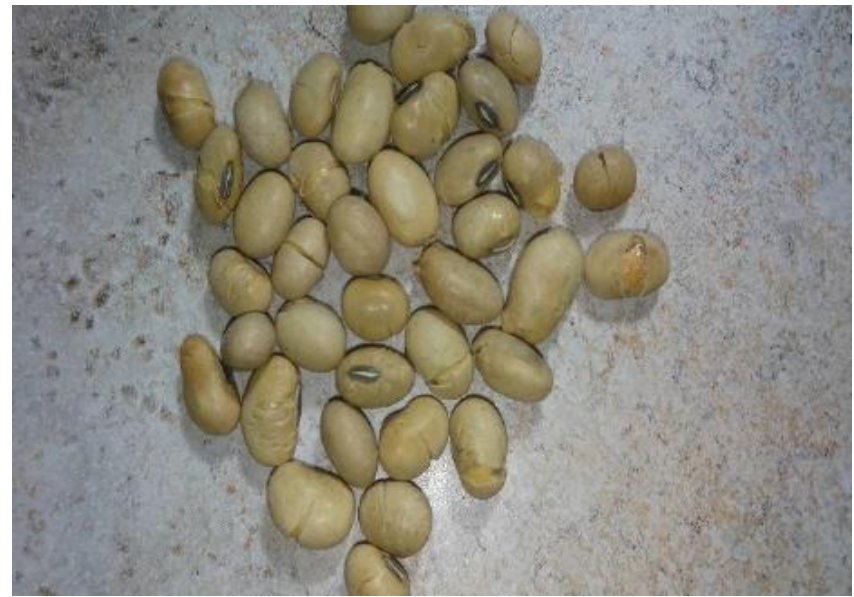

Fig. 12: Soybean Raw Used for Doing Experiments

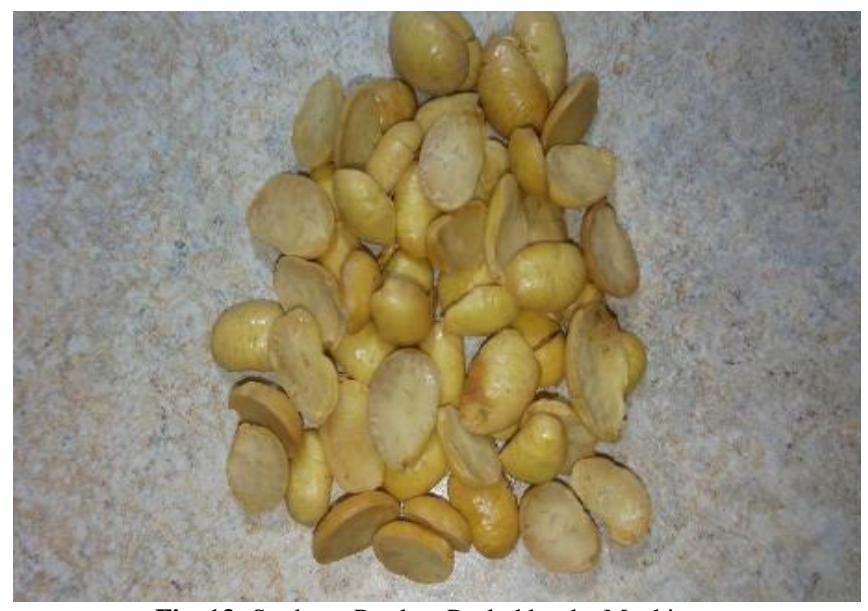

Fig. 13: Soybean Product Peeled by the Machine.

Figs 12 and 13 show the soy bean raw and product before and after peeled by using the machine that could be seen in Fig. 11. In the total number of unarticulated seeds, there are unrecovered and tough seeds. To increase machine performance of the productivity, choosing raw material inputs that are uniform in size and good quality or add equipment to eliminate soybeans that their quality is low or lower than expected.

\section{Conclusions}

The peeling dried soybean machine was designed and fabricated successfully. This is the reason why it is not only the process of peeling soybeans mechanized, but also the performance boosted to 80.06 percent compared to same kinds of machine. The consequence demonstrates that when the distance between the conveyor and the soybean is more than $6 \mathrm{~mm}$ which leads to the complete dropping out of peeling system of soybeans. By contrast, when the distance is less than $6 \mathrm{~mm}$, the soybeans are easily broken into pieces which could not meet the demand of the objectives. Thus, this trial is carried out to reveal that this machine is totally appropriate to food safety standards, particularly when the gap is $6 \mathrm{~mm}$ and the velocity of conveyors is less than $120 \mathrm{rpm}$ during operation.

The machine overcomes the restrictions of others machine in the market such as improving the rate of fine products, and controlling the number of defective products under from 3 to 4 percent. In addition, the machine price is significantly affordable, the maintenance and replacement of parts is both convenient and easy. Especially, this machine is friendly to our environment which is consistent with sustainable development.

\section{Further studies}

In order to make the machine having the higher efficiency, it will be improved and renovated to increase its productivity reaching the expected performance of 35 kilograms per hour. After successful improvements, the study is directly put into the practical manufacturing to satisfy the initial objectives. Maintaining and fixing defects on the machine when increasing productivity should be paid attention. In order to make the machine become friendlier, there will be a controller added on the machine to automatically control the soybean production lines.

Table 4: Nomenclatures

\begin{tabular}{|c|c|}
\hline Definition & Symbol \\
\hline Best Efficient Point & BEP \\
\hline Option & Opt. \\
\hline Revolution per minutes & $\mathrm{rpm}$ \\
\hline Velocity & $\mathrm{v}$ \\
\hline Power & $\mathrm{P}$ \\
\hline Moment & M \\
\hline Stability & $\mathrm{S}$ \\
\hline Force & $\mathrm{F}$ \\
\hline Impact force of shaft & $\mathrm{F}_{\mathrm{X}}$ \\
\hline Molecular weight & G \\
\hline Reaction force at A & $\mathrm{X}_{\mathrm{A}}$ \\
\hline Reaction force at B & $\mathrm{X}_{\mathrm{B}}$ \\
\hline Tangent force & $\mathrm{F}_{\mathrm{b}}$ \\
\hline Opposite reaction at $\mathrm{A}$ & $\mathrm{Y}_{\mathrm{A}}$ \\
\hline Opposite reaction at B & $\mathrm{Y}_{\mathrm{B}}$ \\
\hline Pull force of the conveyor & $\mathrm{R}$ \\
\hline The torque & $\mathrm{W}_{\mathrm{j}}$ \\
\hline The torque reaction & Woj \\
\hline Shaft diameter & $\mathrm{d}$ \\
\hline
\end{tabular}

\section{References}

[1] Tran Van Dich, Manufacturing Technology, Ha Noi Science and Engineering Publisher, Vietnam, 2008.

[2] Nguyen Huu Loc, Fundamentals of Machine Design, Ho Chi Minh city National University Publishing, Vietnam, 2008.

[3] Ninh That Ton, Fit Tolerance, Education publishing.

[4] Tran Van Dich, Manufacturing Technology Design Project, Ha Noi Science and Engineering Publishing, Vietnam, 2005.

[5] Nguyen Dac Loc, Manufacturing Technology Notebook (chapter 1, 2 and 3), Ha Noi Science and Engineering Publishing, Vietnam, 2007. 
[6] Bridgestone, Conveyor Belt Design Manual, Vietnam, 2010.

[7] Trinh Chat, Le Van Uyen, Calculating Mechanism Motion Systems, Chapter 1, Educational Publisher, Vietnam, 2006.

[8] Do Quoc Kien, Strength of Materials, Ho Chi Minh city National University Publisher, Vietnam, 2003.

[9] Akaaimo D.I. and A.O. Raii, Some Physical and Engineering Properties of Prosopis Africana Seed. Biosystems Engineering 95 (2), 197-20, 2006.

[10] Perkins, E., Composition of soybeans and soybean products, Practical Handbook of Soybean Processing and Utilization, Erickson, E.R., Ed., AOCS Press, Champaign, IL, 1995.

[11] C.N Agulanna and E.C. Oriaku, Design and Fabrication of a MicroScale Wet Process Soya-Bean De-Coating Machine, Journal of Emerging Trends in Engineering and Applied Sciences, (JETEAS) 4(1): 149-155, 2013

[12] Amin, M.N., M.A. Hossain, and K.C. Roy, Effects of moisture content on some physical properties of lentil grains, Journal of Food Engineering, 65, 83-87, 2004.

[13] Aviara, N.A., Shittu, S.K., and Haque M.A., Physical properties of guna fruits relevant in bulk handling and mechanical processing Int. Agrophysics, 21, 7-16, 2007.

[14] Olajide, J.D. and J.C. Igbeka, Some physical properties of groundnut kernels, Journal of Food Engineering, 58, 201-204, 2003. 